\title{
Effect of uterine distension and oestrogen treatment on gap junction formation in the myometrium of the rat
}

\author{
D. Claire Wathes and D. G. Porter \\ Department of Anatomy, The Medical School, Bristol BS8 ITD, U.K.
}

\begin{abstract}
Summary. Gap junctions were present in the myometrium of 1 out of 5 rats on Day 21 of pregnancy, 4 out of 5 on the morning of Day 22, 7 out of 7 during parturition and 1 out of 3 on Day 1 post partum. Their frequency (number per mm membrane) at these time periods increased from 0.30 to 2.20 and 6.48 and then decreased to 0.31 .

Ten ovariectomized post-partum rats were fitted with an intrauterine balloon in one horn for recording pressure changes. Control rats maintained continuous pressure cycles. In rats given $7.5 \mu \mathrm{g}$ oestradiol-17 $\beta$ the frequency of intrauterine pressure cycles decreased from about 50 per hour to 4.3 per hour $15 \mathrm{~h}$ later, but the maximum rate of rise of uterine pressure cycles increased significantly from $7.2 \pm$ 0.95 to $11.3 \pm 1.85 \mathrm{mmHg} \mathrm{sec}-1(n=5, P<0.05)$. The overall number of gap junctions per mm membrane in the oestrogen-treated rats was 7.37 in the horns equipped with balloons and 1.03 in the empty horns, compared with 0.97 and none respectively in the control rats. The increased rate of rise of pressure in the oestrogen-treated myometrium indicated improved coupling between cells and this was associated with a high frequency of gap junctions. Both oestrogen treatment and distension.(from the balloon) appeared to cause some gap junctions to form, but numbers equivalent to those at parturition were only obtained in animals in which these two treatments were combined.
\end{abstract}

\section{Introduction}

Gap junctions are involved in the formation of low resistance pathways between cells (Barr, Dewey \& Berger, 1965). Gap junctions are absent from the myometrium during early pregnancy in the rat and sheep but their numbers increase just before and during parturition (Garfield, Sims, Kannan \& Daniel, 1978; Garfield, Rabideau, Challis \& Daniel, 1979). It is thought that their appearance is important in the co-ordination of uterine activity at this time. Gap junctions form spontaneously in myometrium cultured in vitro and their formation is increased by oestrogen and decreased by inhibitors of both prostaglandin and protein synthesis (Garfield, Kannan \& Daniel, 1980a; Garfield, Merrett \& Grover, 1980b). The significance of these findings for the physiological regulation of uterine muscle is uncertain as there are many discrepancies between in-vitro and in-vivo data relating to the myometrium (Finn \& Porter, 1975).

There is some confusion over the need for gap junctions for electrical propagation in the myometrium. There is evidence that the myometrium of mid-pregnant rats is able to propagate action potentials in vitro (Kuriyama \& Suzuki, 1976), yet the data of Garfield et al. (1978) in vivo indicate that gap junctions are not present until shortly before parturition. This discrepancy has led Peracchia (1980) to question the absence of gap junctions during early pregnancy. We therefore wished to repeat the observations of Garfield et al. (1978) on the incidence of gap 
junctions in late pregnancy in the rat, and further to determine whether the improved myometrial co-ordination which occurs in vivo following oestrogen treatment, as reported by Downing, Lye, Bradshaw \& Porter (1978), is associated with changes in the numbers of gap junctions.

\section{Materials and Methods}

\section{Animals}

Wistar rats from the closed colony at Bristol University were used. The median time of parturition under standard lighting conditions (light from 06:00 to 20:00 h) is 13.13 h on Day 22 of gestation (Lincoln \& Porter, 1976), the day of finding vaginal plugs being Day 1.

Experiment 1. Five rats were killed by decapitation between 09:00 and 11:00 h on each of Days 21 and 22 of pregnancy. Trunk blood was collected into iced heparinized tubes and plasma was separated by centrifugation at $1500 \mathrm{~g}$ for progesterone assay (see below). The uterus was prepared for electron microscopy as described below. A further 7 pregnant rats were examined at frequent intervals from the morning of Day 22 until they started to litter. They were then killed during labour following the parturition of 1-7 young and blood and uterine tissue were obtained as above. A further 3 rats were killed on Day 1 post partum.

Experiment 2. Ten rats were bilaterally ovariectomized on Day 1 post partum and were fitted with an intrauterine pressure recording balloon containing $0.45 \mathrm{ml}$ water as described previously (Downing et al., 1978). After a $48 \mathrm{~h}$ recovery period the balloon catheters were connected to Bell and Howell pressure transducers and intrauterine pressure was recorded continuously on a Grass Model $7 \mathrm{c}$ polygraph at a chart speed of $3 \mathrm{~mm} \mathrm{~min}^{-1}$. After a $5 \mathrm{~h}$ initial recording period the chart speed was increased to $3 \mathrm{~mm} \mathrm{sec}^{-1}$ and about 8 pressure cycles were recorded. The chart speed was then returned to $3 \mathrm{~mm} \mathrm{~min}^{-1}$. Alternate rats received s.c. injections of $7.5 \mu \mathrm{g}$ oestradiol-17 $\beta$ in corn oil, or corn oil only. After a further $15 \mathrm{~h}$ of continuous monitoring of intrauterine pressure the chart speed was again increased for a further series of at least 5 pressure cycles. The animals were then killed as described above. By this time the uterus had undergone partial involution so the recording balloon filled the entire uterine lumen.

The traces were analysed in $1 \mathrm{~h}$ sections for frequency of intrauterine pressure cycles greater than $10 \mathrm{mmHg}$. The high-speed recordings were used to estimate the rates of rise of pressure. The 'overall' rate of rise (from the start of the pressure cycles to peak amplitude) and 'maximum' rate of rise for each pressure cycle were expressed in $\mathrm{mmHg} \mathrm{sec}-1$ (Downing et al., 1978).

\section{Electron microscopy}

The method used was similar to that described by Garfield et al. (1980a). Fixative ( $30 \mathrm{ml}$ of $2 \%$ glutaraldehyde, $1 \mathrm{~mm}-\mathrm{CaCl}_{2} \cdot 2 \mathrm{H}_{2} \mathrm{O}$ and $4 \cdot 5 \%$ sucrose in $0.1 \mathrm{M}$-sodium cacodylate buffer, $\mathrm{pH} \mathrm{7.2)} \mathrm{was} \mathrm{injected} \mathrm{into} \mathrm{the} \mathrm{abdominal} \mathrm{cavity} \mathrm{immediately} \mathrm{after} \mathrm{death} \mathrm{and} \mathrm{left} \mathrm{for} 20 \mathrm{~min}$. The uterus was then removed and a section of uterus was taken from the centre of each horn. Each section was sliced thinly $(1-2 \mathrm{~mm})$ and placed in fresh fixative for a further $2 \mathrm{~h}$ at room temperature. Tissue was then stored in $0.1 \mathrm{M}$-cacodylate buffer at $4^{\circ} \mathrm{C}$. Small pieces of tissue were postfixed in $1 \%$ osmium tetroxide in $0.1 \mathrm{M}$-cacodylate buffer for $1 \mathrm{~h}$. They were then

\section{PLATE 1}

Fig. 1. Myometrium from the balloon-filled horn of an oestrogen-treated rat. Arrows indicate gap junctions. $\times 15750$.

Fig. 2. Detail of Fig. 1. $\times 74000$.

Fig. 3. Gap junction showing the typical 7-lined membrane structure. $\times 129000$. 
PLATE 1
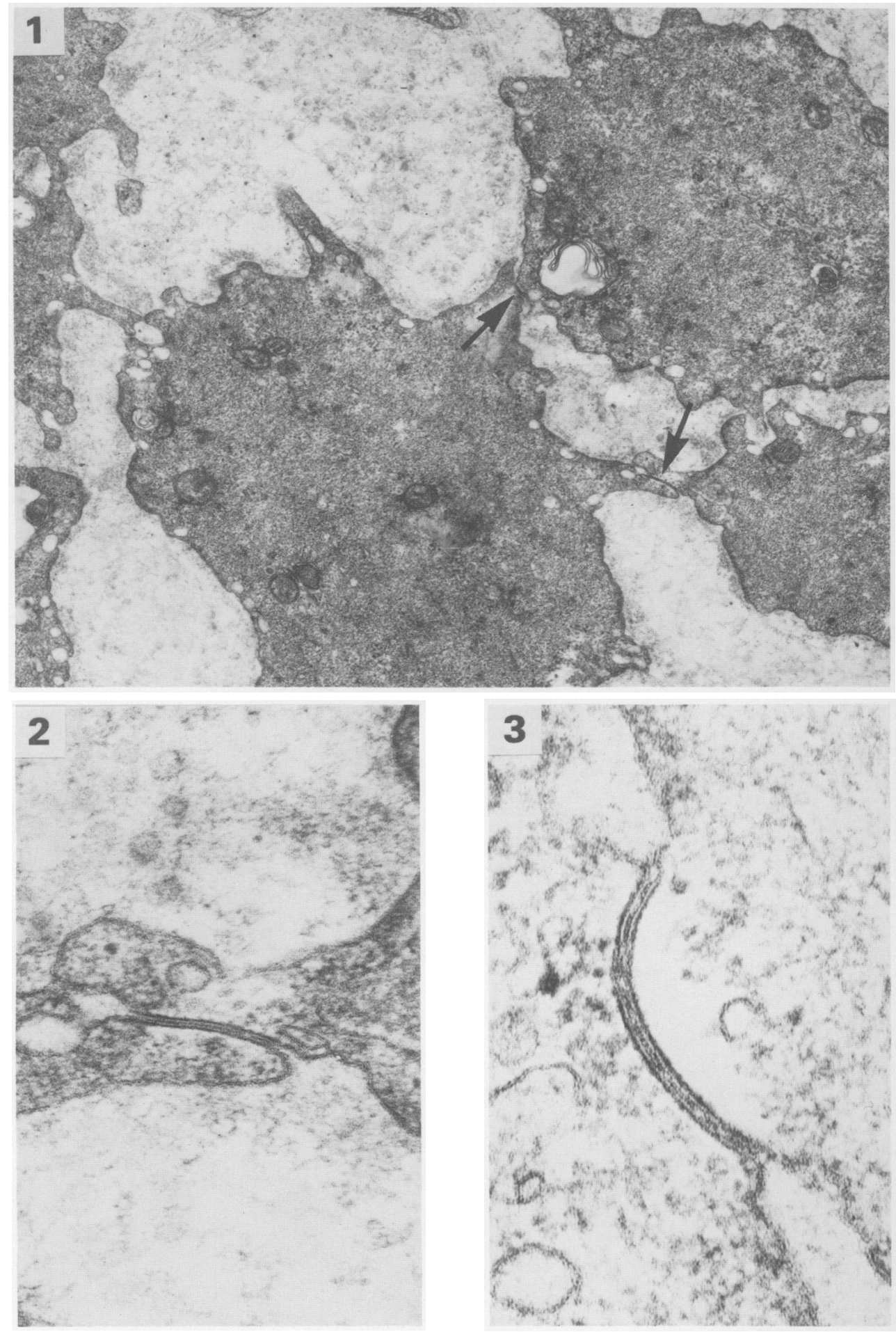

(Facing p. 498) 
stained with $2 \%$ uranyl acetate for $45 \mathrm{~min}$, dehydrated in graded ethanols and embedded in araldite.

The tissue was orientated in order to cut the outer longitudinal muscle in cross section. Silver sections were cut on a Sorvall Porter-Blum MT2 ultramicrotome and mounted on celloidincoated copper 300 mesh grids. Sections were stained with uranyl acetate and lead citrate and viewed on a Philips 300 electron microscope at $80 \mathrm{kV}$.

\section{Quantitative measurements}

Random areas were selected on sections of each tissue sample and a series of 20-25 micrographs were taken and printed at a magnification of $\times 31250$ on $20 \times 25 \mathrm{~cm}$ paper. The length of smooth muscle cell membrane on each print was estimated by the method described by Garfield et al. (1980a) by placing a transparent test grid (Weibel, 1973) over each print and counting the number of intersections between the grid and the membrane. The following formula was then used:

$$
\mathrm{B}=\frac{\pi}{2} \times \frac{\mathrm{I}}{\mathrm{L}} \times \mathrm{A} \times \mathrm{CF}
$$

where $B=$ length of membrane, $I=$ average number of intersects determined from two estimates taken at right angles to one another; $L=$ total length of probe lines $=156.8 \mathrm{~cm} ; A=$ area of photograph examined in the grid system $=434.5 \mathrm{~cm}^{2}$, and $\mathrm{CF}=$ correction factor for magnification. The accuracy of this method was compared with the more laborious process of measuring the actual length of membrane per print and a correlation coefficient of $r^{2}=0.986$ ( $P$ $<0.01, n=13$ ) was obtained between the two methods.

Each suspected gap junction seen in the photographs was enlarged as far as possible from the negative. Gap junctions were defined as membrane structures with either 5 or 7 lines (Pl. 1, Figs $1-3)$. The number of gap junctions per mm of membrane was estimated for each tissue.

\section{Progesterone radioimmunoassay}

Method. The assay method was based on that of Haresign, Foster, Haynes, Crighton \& Lamming (1975). Plasma samples $(0.1 \mathrm{ml}$ in duplicate) were transferred to test tubes and extracted with $2 \mathrm{ml}$ petroleum ether (BDH Analar, boiling point $40-60^{\circ} \mathrm{C}$ ) for $5 \mathrm{~min}$ on a Denley multivortex mixer at a machine speed of 35 . The aqueous phase was frozen at $-15^{\circ} \mathrm{C}$ for $30 \mathrm{~min}$, then the organic phase was decanted to a second set of tubes and evaporated to dryness. Recovery of progesterone during this extraction procedure was estimated as follows: $\left[{ }^{3} \mathrm{H}\right.$ ]progesterone $(0.1 \mathrm{ml}$ in ethanol) was added to 8 extraction tubes and dried down. Plasma $(0.1 \mathrm{ml})$ was added to each tube and these were mixed and incubated at $30^{\circ} \mathrm{C}$ for 15 min before ether extraction.

Starting from a stock solution of $100 \mu \mathrm{g}$ progesterone (Sigma Chemical Co., London) $/ \mathrm{ml}$ ethanol, serial dilutions were made to give 10 standards ranging from 1 to $0.1 \mathrm{ng}$ progesterone $/ \mathrm{ml}$ in phosphate-buffered saline (PBS, $0.1 \mathrm{M}, \mathrm{pH} 7 \cdot 1$, containing $0.1 \%$ of both gelatin and sodium azide). For each standard, $100 \mu \mathrm{l}$ were pipetted into assay tubes in triplicate. Buffer $(100 \mu \mathrm{l})$ was added to each of the extracted samples to equalize the reagent volumes, then $100 \mu \mathrm{l}$ antiserum (BF 465, raised in a goat against progesterone-1 $1 \alpha$-succinyl-bovine serum albumin) was added to each sample and standard tube at a concentration of $1: 3000$. After this [1,2,6,7${ }^{3} \mathrm{H}$ ]progesterone (sp. act. 4.07 TBq/mmol; Radiochemical Centre, Amersham, U.K.) was added at a concentration of 10000 c.p.m. $/ 100 \mu \mathrm{l}$. All tubes were vortexed and left to incubate for $4-24 \mathrm{~h}$ at $4^{\circ} \mathrm{C}$.

To separate bound and free steroid $0.2 \%$ activated charcoal (Sigma Chemical Co., London) and $0.1 \%$ dextran (clinical grade, Sigma) in $0.5 \mathrm{ml}$ PBS were added to each tube, incubated for 
$10 \mathrm{~min}$ at $4^{\circ} \mathrm{C}$ and centrifuged at $1500 \mathrm{~g}$ for a further $10 \mathrm{~min}$ at $4^{\circ} \mathrm{C}$. The supernatants were decanted into small scintillation tubes, and $2.5 \mathrm{ml}$ scintillation fluid were added to each $(0.4 \%$ PPO, Fisons, in toluene). The tubes were incubated at $70^{\circ} \mathrm{C}$ for $20 \mathrm{~min}$, capped, vortexed, and the labelled progesterone was allowed to equilibrate between the aqueous and organic phases. The tubes were then counted for $5 \mathrm{~min}$ on a Packard liquid scintillation spectrometer with an efficiency for tritium of $45 \%$.

Validation. A range of steroids were tested for their cross-reaction with the antiserum. The only ones which showed a cross-reaction of $>0 \cdot 1 \%$ were $11 \alpha$-hydroxypregn-4-ene-3,20 dione, $74 \% ; 11 \beta$-hydroxypregn-4-ene-3,20 dione, $10.0 \%$; $5 \alpha$-pregnane-3,17-dione, $4.4 \%$; $5 \beta$-pregnane3,17 -dione, $2.8 \%$; and $20 \alpha$-hydroxypregn-4-ene-3-one, $1.4 \%$. Accuracy was assessed by adding known quantities of progesterone to $0.1 \mathrm{ml}$ aliquots of plasma containing $34 \mathrm{pg}$ progesterone and assaying the extracts. The mean \pm s.e.m. concentrations for 4 samples in each determination were: for $12 \mathrm{pg}$ added, $46 \pm 7 \cdot 3 \mathrm{pg}$ measured ( $100 \%$ recovery); for $24 \mathrm{pg}$ added, $66 \pm 6.2 \mathrm{pg}$ measured (112\% recovery); for $50 \mathrm{pg}$ added, $87 \pm 7.3 \mathrm{pg}$ measured (104\% recovery); for $100 \mathrm{pg}$ added, $129 \pm 9.2 \mathrm{pg}$ measured ( $96 \%$ recovery); and for $250 \mathrm{pg}$ added, $243 \pm 15.5 \mathrm{pg}$ measured ( $86 \%$ recovery). Water and solvent blanks contained $<4 \mathrm{pg} /$ tube. Sensitivity, defined as twice the s.d. of the zero value, was $6 \mathrm{pg} /$ tube. The inter- and intra-assay coefficients of variation calculated by the method of Snedecor (1952) were $12.6 \%$ and $10.7 \%$ respectively. The recovery of radioactive progesterone from $0.1 \mathrm{ml}$ aliquots of plasma was $76.5 \pm 2.44 \%$ ( 9 assays).

\section{Statistics}

The data on gap junctions did not show normal distributions and were therefore compared by the Mann-Whitney test or the Wilcoxon signed rank test for paired samples from the same rat in Exp. 2. The data on uterine contractions were analysed using a Student's $t$ test for paired samples (Snedecor \& Cochran, 1967).

\section{Results}

\section{Experiment 1}

On Day 21 of pregnancy gap junctions were found in the myometrium of only 1 of the 5 rats examined and these were small ( $<200 \mathrm{~nm}$ in length, $n=2)$. The number of gap junctions was greater in 3 of the 5 rats examined on the morning of Day 22 (Text-fig. 1) and they were larger, with a median length of $254 \mathrm{~nm}$ and a maximum of $736 \mathrm{~nm}(n=32)$. Five rats littered between 11:10 and 17:30 h on Day 22 and the remaining two at 11:15 and 14:45 h on Day 23. Gap junctions were present in the myometria of all these animals and were of a similar size (median length $=251 \mathrm{~nm}, n=57$ ) to those in the Day 22 pre-partum group. At $24 \mathrm{~h}$ post partum a single small gap junction was seen in 1 of the 3 rats examined. The number of gap junctions and the length of membrane surveyed were summed for each of the four time intervals examined to give an overall estimate of the number of gap junctions per mm membrane. The figures were 0.30 on Day 21 (2 gap junctions in $6693 \mu \mathrm{m}), 2.20$ on the morning of Day $22(26$ in $11832 \mu \mathrm{m}), 6.48$ during parturition $(55$ in $8491 \mu \mathrm{m})$ and 0.31 at 1 day post partum $(1$ in $3211 \mu \mathrm{m})$.

The mean \pm s.e.m. plasma progesterone levels were $33.2 \pm 3.14 \mathrm{ng} \mathrm{ml}^{-1}$ on Day 21 and $10.7 \pm 4.89 \mathrm{ng} \mathrm{ml}^{-1}$ on the morning of Day 22. During parturition the progesterone levels were $3.3 \pm 0.14 \mathrm{ng} \mathrm{ml}^{-1}$ on Day 22 and $1.7 \pm 0.07 \mathrm{ng} \mathrm{ml}^{-1}$ on Day 23. One of the Day 22 preparturient rats with relatively few gap junctions (Text-fig. 1) had a progesterone level of 29.4 $\mathrm{ng} \mathrm{ml} \mathrm{m}^{-1}$, suggesting that it would not perhaps have littered until Day 23 (Lincoln \& Porter, 1979). Although the fall in the mean progesterone concentrations occurred at the same time that the gap junction population was increasing there was no significant negative correlation between the two sets of data. 


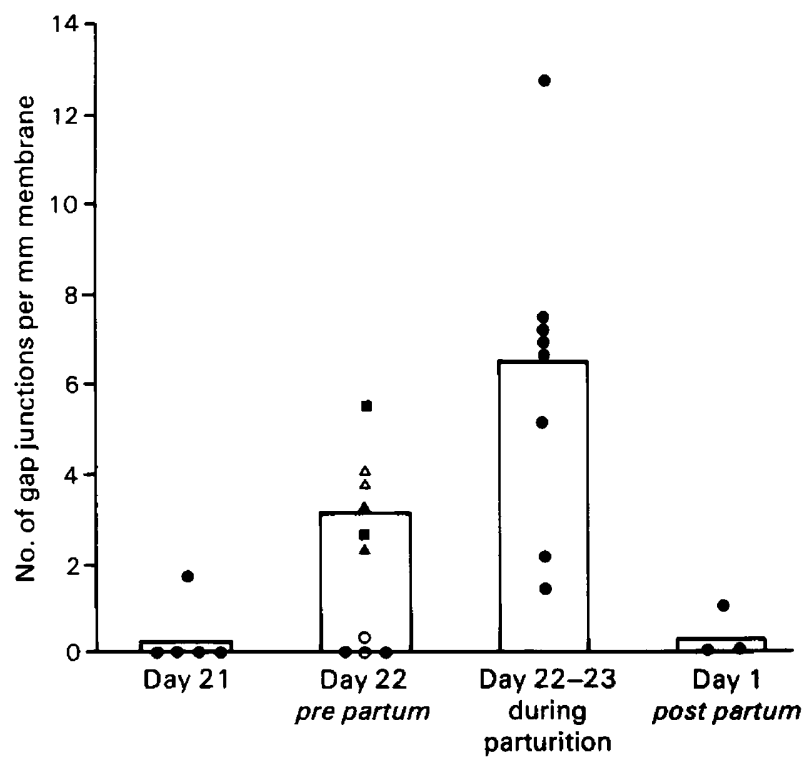

Text-fig. 1. Diagram to show the frequency with which gap junctions were found at different times relative to parturition in the rat. The bar shows the total number of gap junctions per total length of membrane surveyed at each time interval. On Day 22 two samples, indicated by the same symbol, were examined from each rat, otherwise each point represents a different animal. There were significant increases between Days 21 and 22 and between Days 22 and parturition $(P<0.05$ for both) followed by a significant decrease by Day 1 post partum $(P<0.05)$.

The rats used in the experiments were carrying between 4 and 13 young $(8.9 \pm 0.68$ s.e.m.). There was no correlation between the number of young and the number of gap junctions.

\section{Experiment 2}

In control rats intrauterine pressure cycles continued with few interruptions at a frequency of about $50 \mathrm{cycles} / \mathrm{h}$ and an amplitude of $20-30 \mathrm{mmHg}$ throughout the $20 \mathrm{~h}$ study period (Text-fig. 2). Oestrogen-treated rats showed a similar pattern during the $5 \mathrm{~h}$ before treatment but, by $3 \mathrm{~h}$ after injection, the pressure cycles became interspersed with periods of uterine quiescence so that in the interval between the 13th and 15th $\mathrm{h}$ after injection there were only $4.3 \pm 1.85$ (mean \pm s.e.m.) pressure cycles (Text-figs 2 and 3). The average and maximum rates of rise of intrauterine pressure cycles were similar in both groups before treatment and in the control group after treatment (Table 1). However, at $15 \mathrm{~h}$ after oestrogen treatment there had been a small but

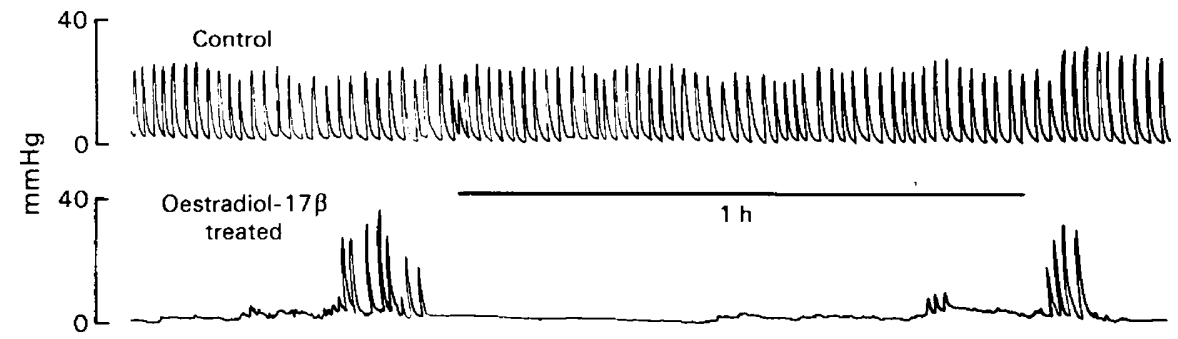

Text-fig. 2. Intrauterine pressure record taken $14 \mathrm{~h}$ after an injection of corn oil or $7.5 \mu \mathrm{g}$ oestradiol-17 $\beta$. 


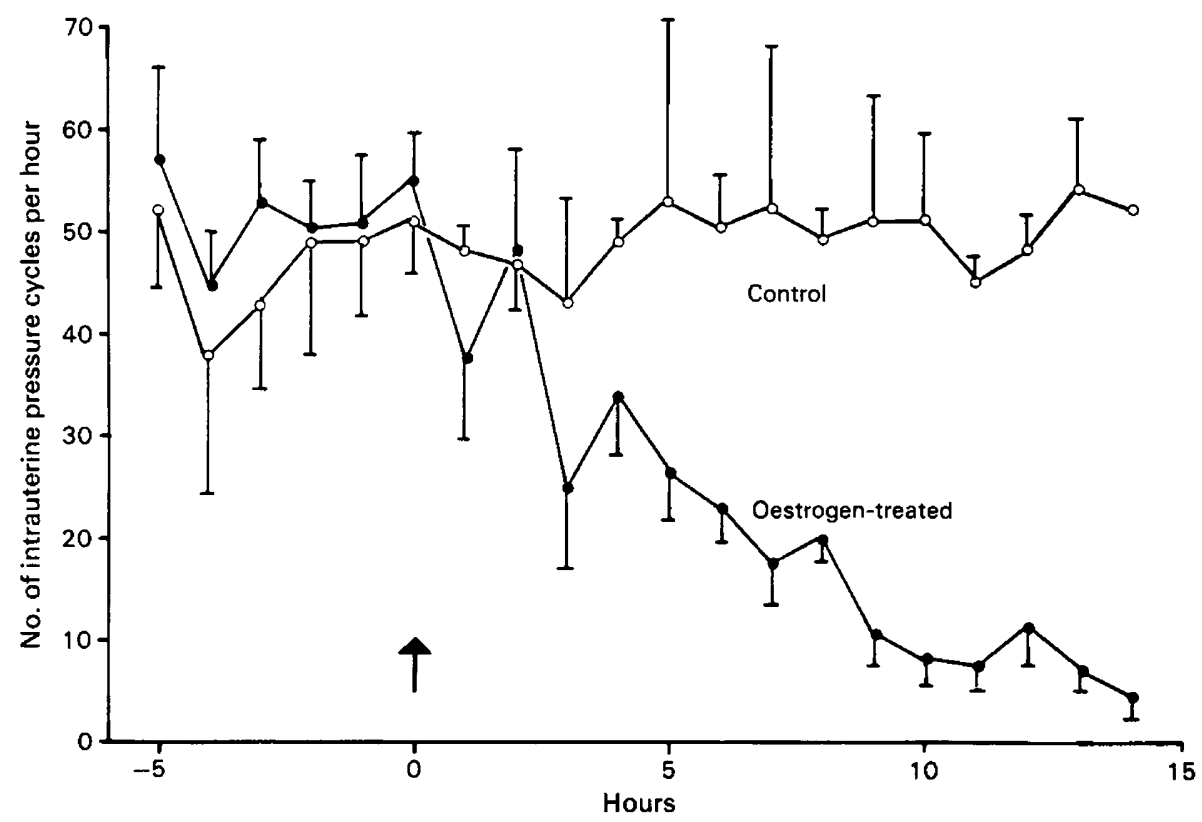

Text-fig. 3. The frequency of intrauterine pressure cycles in rats before and after an injection (arrow) of corn oil or $7.5 \mu \mathrm{g}$ oestradiol-17 $\beta$. Values are mean \pm s.e.m. for 4 or 5 rats per group.

Table 1. The effect of oestrogen on uterine pressure cycles in the rat $\dagger$

\begin{tabular}{|c|c|c|c|c|}
\hline & \multicolumn{2}{|c|}{ Control } & \multicolumn{2}{|c|}{ Oestradiol-17 $\beta$} \\
\hline & Start & Finish & Start & Finish \\
\hline $\begin{array}{l}\text { Average rate of rise of uterine } \\
\text { pressure cycles }\left(\mathrm{mmHg} \mathrm{sec}^{-1}\right)\end{array}$ & $2.8 \pm 0.53(4)$ & $3.2 \pm 0.73(4)$ & $2.9 \pm 0.32(5)$ & $3 \cdot 7 \pm 0.52^{*}(5)$ \\
\hline $\begin{array}{l}\text { Maximum rate of rise of uterine } \\
\text { pressure cycles }\left(\mathrm{mmHg} \mathrm{sec}^{-1}\right)\end{array}$ & $6 \cdot 3 \pm 1 \cdot 38(4)$ & $7 \cdot 1 \pm 1 \cdot 63(4)$ & $7.2 \pm 0.95(5)$ & $11 \cdot 3 \pm 1 \cdot 85^{*}(5)$ \\
\hline
\end{tabular}

Values are mean \pm s.e.m. for the no. of rats indicated in parentheses. One control rat broke its catheter and has been omitted.

* Significantly greater than value at start, $P<0.05$ (paired Student's $t$ test).

$\dagger$ Recordings were made just before treatment and $15 \mathrm{~h}$ after an injection of $75 \mu \mathrm{l}$ corn oil or $7.5 \mu \mathrm{g}$ oestradiol-17及 in corn oil.

significant increase in the average rate of rise of pressure, and a larger increase in the maximum rate of rise $(P<0.05)$.

In the oestrogen-treated rats gap junctions were found in the myometrium of the horn containing the balloon with a frequency similar to that seen during parturition (41 gap junctions in $5565 \mu \mathrm{m}$ membrane $=7.37$ per $\mathrm{mm}$ ). However, in 3 of the 5 oestrogen-treated animals no gap junctions were seen in the empty horn (Text-fig. 4) and the overall incidence was only 1.03 per $\mathrm{mm}$ (7 in $6780 \mu \mathrm{m}$ membrane). In the control rats gap junctions were occasionally present in the balloon-filled horn ( 6 in $6180 \mu \mathrm{m}=0.97$ per $\mathrm{mm}$ ) but they were never seen in the other horn although $9000 \mu \mathrm{m}$ were surveyed. Overall there were significantly more gap junctions present in the oestrogen-treated animals than in the controls $(P<0.01)$ and in individual rats there were significantly more gap junctions in the balloon-filled horn than in the empty one $(P<0.01)$.

The gap junctions in the oestrogen-treated horn with the balloon ranged from 61 to $751 \mathrm{~nm}$ 


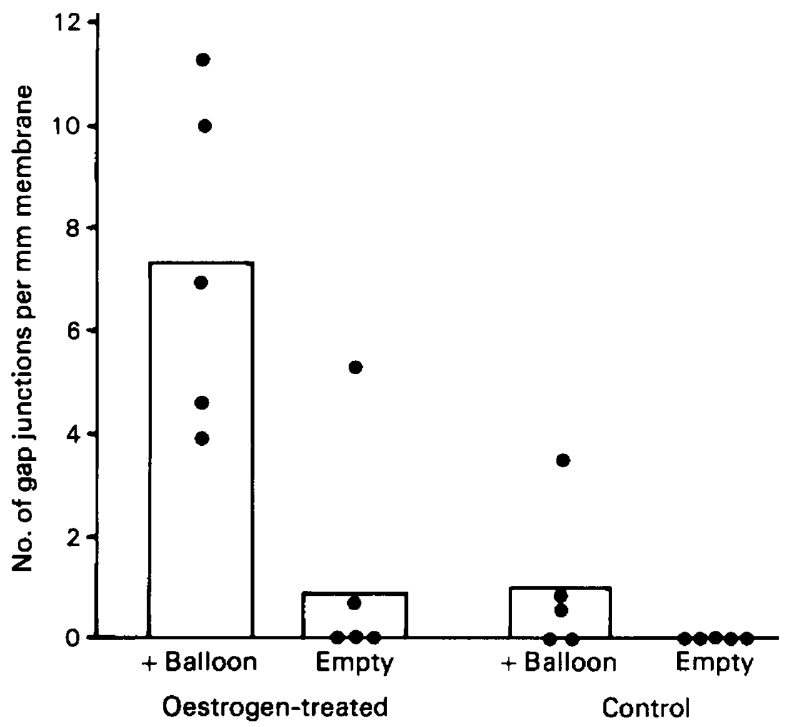

Text-fig. 4. Diagram to show the frequency with which gap junctions were found in ovariectomized post-partum rats fitted with a balloon. Animals were given a s.c. injection of $7.5 \mu \mathrm{g}$ oestradiol-17 $\beta$ in corn oil, or corn oil only and were killed $15 \mathrm{~h}$ later. Each point represents the sample from one animal and the bar shows the total number of gap junctions per total length of membrane surveyed. Oestrogen-treated rats had significantly more gap junctions than did the controls $(P<0.01)$ and balloon-filled horns contained more gap junctions than empty horns $(P<0.01)$.

in length with a median of $224(n=41)$. In the empty horn the median size was $152 \mathrm{~nm}(n=7)$ and in the control rats it was only $128 \mathrm{~nm}(n=6)$.

\section{Discussion}

Gap junctions are low-resistance pathways found between both excitable and non-excitable cells (Peracchia, 1980; Hertberg, Lawrence \& Gilula, 1981). Garfield et al. (1978) have shown that gap junctions appear in the myometrium of the rat shortly before parturition. In the sheep, gap junctions were not seen before Day 100 of gestation but a few were present between Days 127 and 132 and both the number and size increased at term (Garfield et al., 1979). The results given in the present paper confirm these findings in the rat, with gap junctions being seen in only 1 of 5 rats on Day 21, 4 out of 5 rats on the morning of Day 22 and in all 7 animals killed during parturition. They had almost disappeared by $24 \mathrm{~h}$ after littering. We have also confirmed that gap junctions are occasionally present in the sheep myometrium between Days 127 and 136, but the numbers increase significantly in the period from $1 \mathrm{~h}$ before until $2 \mathrm{~h}$ after parturition (D. C. Wathes, unpublished observations).

The present study shows that the increase in the rate of rise of intrauterine pressure cycles which is induced by oestrogen treatment (Downing et al., 1978) is accompanied by a significant increase in the population of gap junctions in the myometrium. Coren \& Csapo (1963) postulated that the rate of rise of intrauterine pressure was an indication of the degree of co-ordination in the uterine muscle. The demonstration of a relationship between the rate of rise of pressure and the number of gap junctions supports this hypothesis since it has been established that the gap junctions provide low resistance coupling between cells (see review by Peracchia, 1980). 
Anderson, Kawarabayashi \& Marshall (1981) have recently correlated electrical and mechanical activity in uterine strips collected from rats between Day 17 of pregnancy and parturition. There was a gradual decline in membrane potential during this period and an alteration in the pattern of action potentials from plateau-type single spikes on Day 17 to repetitive spikes on Day 21 and during parturition. The frequency of mechanical contractions declined but the contractions become longer and more regular. The train of spikes and the uterine contractions also became increasingly well synchronized over this period. This provides further evidence that the formation of gap junctions at this time may be related to the more effective co-ordination of myometrial contraction.

Our results also suggest that oestrogen treatment alone may be insufficient to bring the number of gap junctions present in the myometrium up to the level found during parturition because this concentration was achieved only if the uterus was distended by the presence of an intrauterine balloon. Distension alone also induced the formation of a few gap junctions. The fact that both the frequency and the size of gap junctions in the distended horns of oestrogen-treated rats approximated to those in parturient rats suggests that the implantation of a balloon in the uterine horn does not constitute a gross insult. The utrine epithelium adjacent to the balloon appeared completely undamaged. As almost all gap junctions have been lost by $24 \mathrm{~h}$ post partum when the balloons were inserted these must have been acting to induce new gap junctions rather than preserving the old ones.

No differences in electrical activity in balloon-filled or empty uterine horns were found by Ishikawa \& Fuchs (1978) for rats or by Porter, Yoshinaga \& Ford (1974) for guinea-pigs. However, a number of observations on rabbits which were unilaterally pregnant or fitted with a balloon indicated that uterine distension both increased the frequency of pressure cycles and improved the synchrony of contraction between myometrial cells (Kao, 1959; Takeda, 1965; Csapo, 1977). Similarly, Kawarabayashi \& Marshall (1981) have compared the electrical and mechanical activity of the two horns of unilaterally pregnant rats and found that in the non-gravid horn on Day 20 electrical and mechanical activity remained asynchronous, in contrast to the good co-ordination in the gravid horn. It therefore appears that the stretch imposed on the myometrium by the growing conceptuses is an important factor in regulating gap junction formation near term and in facilitating the co-ordinated contractions necessary for parturition. There was no correlation between the number of embryos and the number of gap junctions, but this is not altogether surprising as the uterus surrounding any particular conceptus will be subjected to the same degree of distension.

Changes in electrical and mechanical activity of the myometrium have also been related to a number of endocrine factors including the concentrations of oestrogen and prostaglandin. Ishikawa \& Fuchs (1978) examined in-vivo changes during the oestrous cycle of the rat and found that high circulating levels of oestrogen in pro-oestrus were associated with infrequent but rapidly propagated spike bursts whereas low levels at oestrus were associated with frequent but non-propagated bursts. Work in our own laboratory using suction electrodes has shown that the propagation velocity of spontaneous activity in oestrogen-treated rats is significantly faster than in control animals (C. D. Redstone, unpublished observations). Similarly Garfield et al. (1980a) found that oestrogen treatment of uterine strips in vitro increased gap junction formation. This may also be aided by the action of oestrogen in causing the proliferation of smooth muscle cell processes, thus increasing areas for contact (Bergmann, 1968).

It is possible that both oestrogen and uterine distension also act on gap junction formation via their effects on prostaglandin (PG) synthesis. Csapo (1977) showed that distending the uterus of rabbits using a balloon approximately doubled synthesis of PGF while PGE levels remained unchanged. The rising level of oestradiol-17 $\beta$ at parturition is probably one of the main influences on the alteration in PG synthesis and release at this time (Williams, Dembinska-Kiec, Zmuda \& Gryglewski, 1978; Sterin-Speziale, Gimeno, Bonacossa \& Gimeno, 1980; Challis, 1980). Garfield et al. (1980a) showed that the spontaneous formation of myometrial gap junctions in 
culture could be prevented by the addition of indomethacin to the medium and they suggested (Garfield et al., 1980a, b) that thromboxanes and endoperoxides may be the prostanoids which stimulate gap junction formation.

The absence of gap junctions before Day 22 of pregnancy in the rat may be important in preventing co-ordinated uterine contractions during pregnancy. Therefore the apparently good electrical coupling found in the pregnant rat myometrium by Kuriyama \& Suzuki (1976) before gap junctions are formed remains puzzling. However, the demonstration that gap junctions form spontaneously within $2 \mathrm{~h}$ of culture in vitro (Garfield et al., 1980a) and that they are induced by stretch (present study) must cast doubts on the reliability of data on electrical coupling obtained from strips of myometrium maintained under tension in vitro.

We thank Mr T. Baker for his excellent assistance with the photography, Miss R. M. Graham for typing the manuscript and the M.R.C. for its financial support.

\section{References}

Anderson, G.F., Kawarabayashi, T. \& Marshall, J.M. (1981) Effect of indomethacin and aspirin on uterine activity in pregnant rats: comparison of circular and longitudinal muscle. Biol. Reprod. 24, 359-372.

Barr, L., Dewey, M.M. \& Berger, W.L. (1965) Propagation of action potentials and the structure of the nexus in cardiac muscle. J, gen. Physiol. 48, $797-823$.

Bergmann, R.A. (1968) Uterine smooth muscle fibres in castrate and oestrogen treated rats. J. Cell Biol. 36, $639-648$.

Challis, J.R.G. (1980) Endocrinology of late pregnancy and parturition. Int. Rev. Physiol. 23, 277-324.

Csapo, A.I. (1977) The effects of ovariectomy and stretch on the regulatory profile and activity of the uterus. Prostaglandins 13, 965-973.

Coren, R.L. \& Csapo, A.I. (1963) The intra-amniotic pressure. Am. J. Obstet. Gynec. 85, 470-483.

Downing, S.J., Lye, S.J., Bradshaw, J.M.C. \& Porter, D.G. (1978) Rat myometrial activity in vivo: effects of oestradiol-17 $\beta$ and progesterone in relation to the concentrations of cytoplasmic progesterone receptors. J. Endocr. 78, 103-117.

Finn, C.A. \& Porter, D.G. (eds) (1975) The Uterus. Paul Elek, London.

Garfield, R.E., Sims, S.M., Kannan, M.S. \& Daniel, E.E. (1978) Possible role of gap junctions in activation of myometrium during parturition. $A m$. J. Physiol. 235, C168-C179.

Garfield, R.E., Rabideau, S., Challis, J.R.G. \& Daniel, E.E. (1979) Hormonal control of gap junction formation in sheep myometrium during parturition. Biol. Reprod. 21, 999-1007.

Garfield, R.E., Kannan, M.S. \& Daniel, E.E. (1980a) Gap junction formation in myometrium: control by oestrogens, progesterone and prostaglandins. $\mathrm{Am}$. J. Physiol. 238, C81-C89.

Garfield, R.E., Merrett, D. \& Grover, A.K. (1980b) Gap junction formation and regulation in myometrium. Am. J. Physiol. 239, C217-C228.

Haresign, W., Foster, J.P., Haynes, N.B., Crighton, D.B. \& Lamming, G.E. (1975) Progesterone levels following treatment of seasonally anoestrous ewes with synthetic LH-releasing hormone. J. Reprod. Fert. 43, 269-279.

Hertberg, E.L., Lawrence, T.S. \& Gilula, N.B. (1981) Gap junctional communication. Ann. Rev. Physiol. 43, 479-491.
Ishikawa, M. \& Fuchs, A.-R. (1978) Electrical and mechanical activity of rat uterus in vivo during the oestrous cycle. Am. J. Obstet. Gynec. 132, 611-619.

Kao, C.Y. (1959) Long term observations of spontaneous electrical activity of the uterine smooth muscle. Am. J. Physiol. 196, 343-350.

Kawarabayashi, T. \& Marshall, J.M. (1981) Factors influencing circular muscle activity in the pregnant rat uterus. Biol. Reprod. 24, 373-389.

Kuriyama, H. \& Suzuki, H. (1976) Changes in electrical properties of rat myometrium during gestation and following hormonal treatments. J. Physiol., Lond. 260, 315-333.

Lincoln, D.W. \& Porter, D.G. (1976) Timing of the photoperiod and the hour of birth in rats. Nature, Lond. 260, 780-781.

Lincoln, D.W. \& Porter, D.G. (1979) Photoperiodic dissection of endocrine events at parturition. Anim. Reprod. Sci. 2, 97-115.

Peracchia, C. (1980) Structural correlates of gap junction permeation. Int. Rev. Cytol. 66, 81-146.

Porter, D.G., Yoshinaga, K. \& Ford, J. (1974) Progesterone concentration, intraluminal pressure and electrical activity of the pig uterus. $J$. Endocr. 61, 255-263.

Snedecor, G.W. (1952) Query 92. Biometrics 8, 85-86.

Snedecor, G.W. \& Cochran, W.G. (1967) Statistical Methods, 6th edn. Iowa State University Press, Ames.

Sterin-Speziale, N., Gimeno, M.F., Bonacossa, A. \& Gimeno, A.I. (1980) The effect of oestradiol on isolated rat uterine mobility and on prostaglandin generation. Prostaglandins 26, 233-244.

Takeda, H. (1965) Generation and propagation of uterine activity in situ. Fert. Steril. 16, 113-119.

Weibel, E.R. (1973) Stereological techniques for electron microscope morphometry. In Principles and Techniques of Electron Microscopy: Biological Applications, vol. 3, pp. 237-297. Ed. M. A. Hayat. van Nostrand Reinhold, New York.

Williams, K.I., Dembinska-Kiec, A., Zmuda, A. \& Gryglewski, R.J. (1978) Dual actions of prostacyclin $\left(\mathrm{PG} \mathrm{I}_{2}\right.$ ) on the rat pregnant uterus. Prostaglandins 15, 343-350. 